\title{
Cdo Is Required for Efficient Motor Neuron Generation of Embryonic Stem Cells
}

\author{
Hyebeen Kim ${ }^{1,3}$, Seul-Yi Lee ${ }^{2,3}$, Hyeon-Ju Jeong ${ }^{1,3}$, Jong-Sun Kang ${ }^{1,3}$, Hana Cho ${ }^{2,3}$, Young-Eun Leem ${ }^{1,3}$ \\ ${ }^{l}$ Department of Molecular Cell Biology, Sungkyunkwan University School of Medicine, Suwon, Korea \\ ${ }^{2}$ Department of Physiology, Sungkynnkwan University School of Medicine, Suwon, Korea \\ ${ }^{3}$ Single Cell Network Research Center, Sungkyunkwan University School of Medicine, Suzwon, Korea
}

\begin{abstract}
Background and Objectives: The directed differentiation of pluripotent stem cells into motor neurons is critical for the development of disease modelling and therapeutics to intervene degenerative motor neuron diseases. Cell surface receptor Cdo functions as a coreceptor for Sonic hedgehog (Shh) with Boc and Gasl in the patterning of ventral spinal cord neurons including motor neurons. However, the discrete function of Cdo is not fully understood.

Methods and Results: In this study, we examined the role of Cdo in motor neuron generation by utilizing in vitro differentiation of $\mathrm{Cdo}^{+/+}$and $\mathrm{Cdo}^{-/-}$embryonic stem cells (ESCs). In response to Shh, Cdo ${ }^{-/-}$ESCs exhibited impaired expression of motor neuron specification markers while dorsal interneuron specification markers were significantly increased, compared to $C d o^{+/+}$ESCs. Reactivation of Shh signalling pathway with Smoothened (Smo) agonist (SAG) restored motor neuron specification in $\mathrm{Cdo}^{-1-}$ ESCs. In addition, electrophysiological analysis revealed the immature electrical features of $\mathrm{Cdo}^{-1-}$ ESCs-derived neurons which was restored by SAG.

Conclusions: Taken together, these data suggest that Cdo as a Shh coreceptor is required for the induction of motor neuron generation by fully activating Shh signalling pathway and provide additional insights into the biology of motor neuron development.
\end{abstract}

Keywords: Cdo, Shh coreceptors, Shh signalling pathway, Motor neuron generation, Embryonic stem cells

\section{Introduction}

Neurogenesis is a complex sequence of coordinated events that involve specification, expansion and differentiation of distinct neuronal subtypes $(1,2)$. Generation of

Received: March 5, 2020, Revised: June 8, 2020,

Accepted: June 23, 2020, Published online: August 31, 2020

Correspondence to Young-Eun Leem

Department of Molecular Cell Biology, Sungkyunkwan University School of Medicine, 2066 Seobu-ro, Jangan-gu, Suwon 16419, Korea Tel: +82-31-299-6156, Fax: +82-31-299-6239

E-mail: leemyo@skku.edu

(a) This is an open-access article distributed under the terms of the Creative Commons Attribution Non-Commercial License (http://creativecommons.org/ licenses/by-nc/4.0/), which permits unrestricted non-commercial use, distribution, and reproduction in any medium, provided the original work is properly cited.

Copyright (c) 2020 by the Korean Society for Stem Cell Research distinct neuronal subtypes in the developing spinal cord is regulated by signalling gradients originating from dorsal and ventral organizers $(3,4)$. Shh secreted from notochord and floor plate of the developing ventral neural tube plays a key role in generation of ventral neural subtype, including motor neurons (5-7). Consistently, genetic deletion of Shh leads to severe defects in the neural tube development, including the failure to generate many ventral neuronal subtypes (8). On the other hand, ectopic activation of Shh signalling pathway in dorsal region of neural tube triggers up-regulation of ventral neuronal gene expression accompanied by blocking of dorsal-specific gene expression $(7,9)$. Importantly, the graded activity of Shh signalling pathway regulates specification of ventral neuronal subtypes through regulation of key transcription factors $(2,10)$. Thus, tight regulation of Shh signalling pathway is critical for generation of specific neuronal subtypes. 
Neurons generated in more ventral regions of the neural tube, such as motor neurons require progressively higher concentration of Shh for their induction (2). In response to two- to three-fold changes in Shh concentration, five distinct neuronal subtypes in the spinal cord can be generated in vitro and the position at which each neuronal subtype is generated in vivo is predicted by the Shh concentration which is required for their induction in vivo (3, $5,6)$. Shh signaling pathway is critical for the specification of Nkx2.2-positive neural progenitor, V3 in early developing neural tube and at later stage it is required for the maintenance of Olig2-positive motor neuron progenitors after their initial specification (11-13).

Shh signalling pathway is initiated by Shh binding to the primary receptor Patched-1 (Ptch1) and coreceptors that activate the 7-transmembrane protein, Smo and the downstream transcription factors such as Glioma-associated oncogene (Gli) transcription factors. This signalling activation then induces genes implicated diverse cellular processes including cell specification and differentiation. Cdo and Boc, members of the immunoglobulin (Ig) superfamily, function as Shh coreceptors to induce full activation of Shh signalling pathway together with another coreceptor Gas1 (14-16). Cdo is transiently expressed in the critical organizing regions, such as the prechordal plate and notochord in central nervous system (CNS) development and more persistently in the dorsal region and the roof plate of the developing neural tube $(14,17)$. Cdo deficiency causes multiple defects in CNS, resulting in holoprosencephaly, hydrocephalus, reduced cortical thickness and reduced ventral neural fate patterning $(15,18)$. In Cdo-deficient mice, Shh signalling activity is decreased, leading to the defective specification of ventral neural cell fates in the developing spinal cord as well as holoprosencephaly $(14,17,19)$. The double mutant mice for two Shh coreceptors Cdo and Gasl exhibit a complete loss in the specification of progenitors for the floor plate, V3 interneuron and motor neurons that are dependent on Shh. In addition, Cdo and Boc double knockout mice have revealed that the specification of Olig2-positive motor neuron progenitors appears to be normal in developing neural tube at E10.5, while Cdo and Boc are required for the maintenance of Olig2-positive motor neuron progenitors after the initial specification (14). Coreceptors are required to activate the optimal Shh signal strength required for diverse neuronal subtypes. However, the discrete function of Cdo in motor neuron specification is not fully understood.

In this study, we took advantage of an in vitro differentiation system of Cdo-deficient ESCs to define the role of Cdo in motor neuron specification. Cdo was highly induced prior to the motor neuron specification markers Olig2 and Nkx6.1. In response to Shh, Cdo-deficient ESCs exhibited reduced expression of motor neuron specification genes while dorsal interneuron specification genes were significantly increased, compared to wildtype ESCs. Reactivation of Shh signalling with a Smo agonist SAG restored motor neuron specification in Cdo-deficient ESCs while suppressing dorsal interneuron markers. The electrophysiological analysis revealed that unlike wildtype neurons, Cdo-deficient neurons did not fire repetitive action potentials (APs), which was restored partially by the SAG treatment. Taken together, these data suggest that Cdo as a Shh-coreceptor is required for the specification of motor neurons and the efficient generation of motor neurons.

\section{Materials and Methods}

\section{Mice}

All mouse work was carried out as previously described $(19,20)$. The result of mouse genotyping for the current study is presented in Supplementary Fig. S1. The heterozygous Cdo mutant mice were maintained on a C57BL/6 background. $C d o^{-1-}$ mice on the $\mathrm{C} 57 \mathrm{BL} / 6$ background showed $80 \sim 85 \%$ lethality and the remaining 15 20\% knockout mice died within $4 \sim 12$ weeks of birth. $C d o^{-/-}$ mice that survived beyond the perinatal period, displayed the phenotype of a dome-shaped head, limb weakness and immobility. $C d o^{+/+}$and $C d o^{-/-}$mice were maintained at $23^{\circ} \mathrm{C}$ with a $12 \mathrm{~h}$ light $/ 12 \mathrm{~h}$ dark cycle. Food and water were freely available to mice. These animal experiments were approved by the Institutional Animal Care and Research Advisory Committee at Sungkyunkwan University School of Medicine Laboratory Animal Research Center and complied with the regulations by the institutional ethics committee.

\section{ESC culture and in vitro differentiation into motor neurons}

$\mathrm{Cdo}^{+/+}$and $\mathrm{Cdo}^{-/-}$mouse ESCs (mESCs) were cultured as previously described $(18,21,22)$. Briefly, mESCs were maintained in ES cell growth medium containing 15\% Fetal bovine serum (FBS), $2 \mathrm{mM}$ Glutamate, $0.1 \mathrm{mM}$ Nonessential amino acids, $20 \mathrm{mM}$ HEPES (pH 7.3), $0.1 \mathrm{mM}$ $\beta$-Mercaptoethanol, 1\% Gentamicin and LIF (1,000 U/ml) on $\gamma$-irradiated mouse embryonic fibroblasts (MEFs). To induce neural lineage (NI), MEFs were eliminated by trypsinization followed by incubation in the growth medium on $0.1 \%$ Gelatin-coated dish. mESCs were then in- 
cubated in neural induction medium containing 15\% FBS, $1 \%$ Non-essential amino acids, 1\% Gentamicin, $1 \mathrm{mM}$ Monothioglycerol, $50 \mathrm{ng} / \mathrm{ml}$ Noggin, $20 \mathrm{ng} / \mathrm{ml} \mathrm{FGF-8} \mathrm{and}$ $20 \mathrm{ng} / \mathrm{ml} \mathrm{bFGF}$ for 2 days. To induce motor neuron specfication (MNS), embryoid bodies (EBs) were incubated in motor neuron differentiation medium; ES-culture basal medium-A, 10\% Knockout serum replacement, 1\% N-2 supplement, 1\% ITS Supplement-B, 1\% Ascorbic acid, 1\% Gentamicin, 1\% GlutaMax-I, 0.15\% D-Glucose, $20 \mu \mathrm{g} / \mathrm{ml}$ Heparin, $0.1 \mathrm{mM} \quad \beta$-Mercaptoethanol, $1 \mu \mathrm{M}$ Retinoic Acid (RA) and $100 \mu \mathrm{M}$ Shh for 5 days. To induce motor neuron elongation (Elong), EBs were dissociated into single cells using Accumax (Millipore, Massachusetts, USA) and then, $2 \times 10^{5} / \mathrm{ml}$ cells were replated on poly-DL-ornithine/laminin/matrigel-coated dishes with motor neuron differentiation medium, which contains $10 \mathrm{ng} / \mathrm{ml}$ of BDNF, GDNF, CNTF, and NT-3 instead of $1 \mu \mathrm{M}$ RA and $100 \mu \mathrm{M}$ Shh for additional 4 days.

\section{Cryosection of EBs and immunostaining}

Immunostaining of EBs was carried out as previously described (22). Briefly, EBs were fixed and dehydrated with 4\% Paraformaldehyde (PFA) and followed by sequential Sucrose incubation. After cryo-embedding, $7 \mu \mathrm{m}$ thickness of sectioning was performed with a cryostat microtome (Leica, Vetzlar, Germany). For immunostaining, EB sections were fixed with 4\% PFA for 15 min, permeabilized with $0.5 \%$ Trinon $\mathrm{X}-100$ for $5 \mathrm{~min}$, blocked with 3\% BSA for $30 \mathrm{~min}$ and probed with the following antibodies; Nkx6.1 (F55A12, DSHB, Iowa, USA, $1: 300$ ), Olig2 (ab109186, Abcam, UK, 1 : 300), Islet1 (Isl1) (ab20670, Abcam, $1: 300$ ) or Hb9 (PA5-23407, Invitrogen, Massachusetts, USA, $1: 300)$. After over-night incubation with primary antibodies at $4{ }^{\circ} \mathrm{C}$, cells were labeled with appropriate secondary antibodies (Alexa Fluor 488 goat antirabbit or Alexa Fluor 568 goat anti-mouse antibody (Life technologies, California, USA, $1: 300)$ ). Cells were counterstained with 4',6-diamidine-2-phenylindole dihydrochloride (DAPI, Roche) to show the nuclei. Confocal images were obtained with a LSM-710 Meta confocal fluorescence microscope (Carl Zeiss, Oberhochen, Germany).

\section{Quantitative RT-PCR and RNA sequencing}

Quantitative real-time PCR (qRT-PCR) analysis was performed as previously described (23). Total RNAs were isolated by using Trizol reagent (Invitrogen) following manufacturer's instructions. cDNA synthesis was obtained using with PrimeScript ${ }^{\mathrm{TM}}$ RT reagent kit (TaKaRa, Japan) and analyzed by qRT-PCR using SYBR Premix Ex Taq (TaKaRa). The values were normalized to the level of $L 32$.
Primer sequences are listed in Supplementary Table S1. For RNA sequencing analysis, RNA quality was assessed by Agilent 2100 bioanalyzer using the RNA 6000 Nano Chip (Agilent Technologies, Amstelveen, Netherlands) and RNA quantification was performed with ND-2000 Spectrophotometer (Thermo Scientific, Massachusetts, USA). For control and test RNAs, the library was constructed by using QuantSeq 3' mRNA-Seq Library Prep Kit (Lexogen, Inc., Vienna, Austria) according to the manufacturer's instructions. High-throughput sequencing was carried out as single-end 75 sequencing using NextSeq 500 (Illumina, Inc., California, USA). QuantSeq 3' mRNA-Seq reads were aligned using Bowtie2 (24). Differentially expressed genes were determined based on the counts from unique and multiple alignments using coverage in Bedtools (25). The RT (Read Count) data were processed based on Quantile normalization method using Bioconductor-edgeR within $\mathrm{R}$ ( $\mathrm{R}$ development Core Team, 2016) (26). Gene classification was based on the searches done by DAVID (http:// david.abcc.ncifcrf.gov/) and Medline databases (http://www. ncbi.nlm.nih.gov/).

\section{Electrophysiology}

Coverslips were transferred to a recording chamber mounted to a microscope (Olympus, Tokyo, Japan) for electrophysiological recordings. Experiments were performed on DIV 3 neurons in culture using the whole-cell patch clamp technique. Data were collected using a MultiClamp 700B amplifier (Molecular Devices, California, USA), data acquisition system (Digidata 1550, Molecular Devices), and Igor Pro analysis software (Wavemetrics). The cells were superfused at $2 \sim 3 \mathrm{ml} / \mathrm{min}$ with solution of the following composition; $143 \mathrm{mM} \mathrm{NaCl}, 5.4 \mathrm{mM} \mathrm{KCl}, 5 \mathrm{mM}$ HEPES, $0.5 \mathrm{mM} \mathrm{NaH} \mathrm{PO}_{4}, 0.5 \mathrm{mM} \mathrm{MgCl}, 1.8 \mathrm{mM} \mathrm{CaCl} 2$

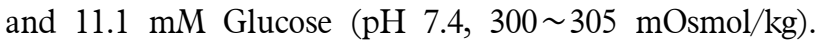
Whole-cell patch clamp recordings were made at room temperature using micropipettes $(3 \sim 5 \mathrm{M} \Omega$, Sutter Instrument, Califormia, USA) filled with an internal solution containing $143 \mathrm{mM}$ K-Gluconate, $15 \mathrm{mM}$ HEPES, $7 \mathrm{mM}$ KCl, $0.1 \mathrm{mM}$ EGTA, $4 \mathrm{mM} \mathrm{Mg-ATP,} 0.3 \mathrm{mM} \mathrm{Na-GTP}$ and $4 \mathrm{mM} \mathrm{Na-Ascorbate}$ ( $\mathrm{pH} \mathrm{7.3,} \mathrm{290} 295 \mathrm{mOsmol} / \mathrm{kg}$ ). The following parameters were measured: (1) the resting membrane potential (RMP), (2) the input resistance (IR, membrane potential changes $(\mathrm{V})$ for given hyperpolarizing current (-30 pA, $500 \mathrm{~min})$ input), (3) after-hyperpolarization (AHP), (4) AP threshold current (current threshold for single action potential generation, $30 \mathrm{~min}$ duration), (5) AP amplitude, (6) AP incidence. Voltage-gated sodium and potassium channels were detected in voltage-clamp mode at a holding potential of $-70 \mathrm{mV}$. The holding po- 
tential was changed in a stepwise fashion from -60 to + $50 \mathrm{mV}$ in $10 \mathrm{mV}$ increments for $1 \mathrm{sec}$ and the voltagegated peak inward current and sustained outward current (between 800 and $900 \mathrm{~min}$ ) were measured for each step.

\section{Statistical analysis}

Values are means \pm SEM or SD as noted in figure legends. Statistical significance was calculated using paired or unpaired two-tailed Student's $t$ test; Differences were considered significant at ${ }^{*} \mathrm{p}<0.05, * * \mathrm{p}<0.01, * * * \mathrm{p}<0.001$.

\section{Results}

\section{Cdo was induced at motor neuron specification stage prior to Olig2 and $N k \times 6.1$ induction}

Using a standard protocol as illustrated in Fig. 1a, we induced differentiation of ESCs into motor neurons. To confirm the sucessful motor neuron differentiation, we have analized the differentiation-associated gene expression at subdivided time points for 2 days of NI (NI1, NI2), 5 days of MNS (MNS-1, MNS-3, MNS-5) and Elong. The expression of stemness genes, such as Nanog and Oct4 was blunted at MNS-1 (Fig. 1b). The motor neuron specification markers, Olig2, Nkx6.1, Hb9 and Isll were robustly elevated at MNS and sharply reduced at Elong (Fig. 1c). The Olig2 expression peaked at MNS-3 and decreased gradually thereafter, while Nkx6.1, Hb9 and Isll levels were highest at MNS-5. In addition, the levels of Shh signalling components were examined during the differentiation (Fig. 1d). The level of Shh increased gradually during neuronal differentiation and robustly elevated at Elong. The expression of the primary Shh receptor gene, Ptchl was progressively elevated during neuronal differentiation and slightly decreased at Elong. In contrast, Glil and Gli2 expression decreased continuously and almost diminished at Elong. The expression of Gli3 gradually in- a

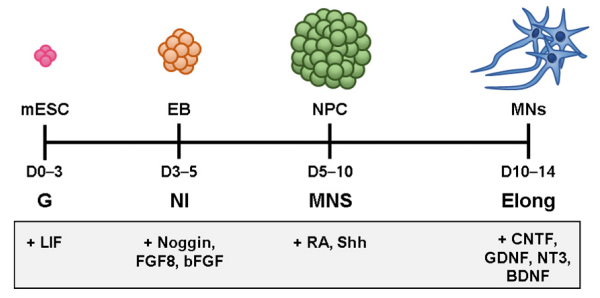

b
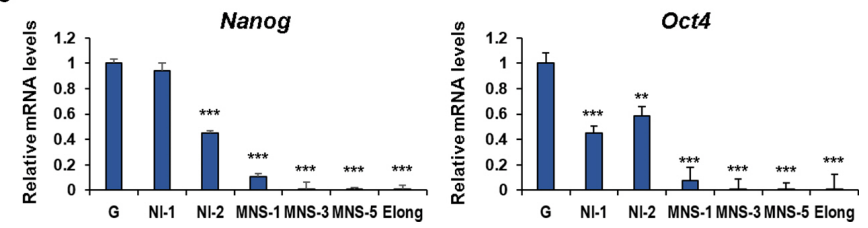

C
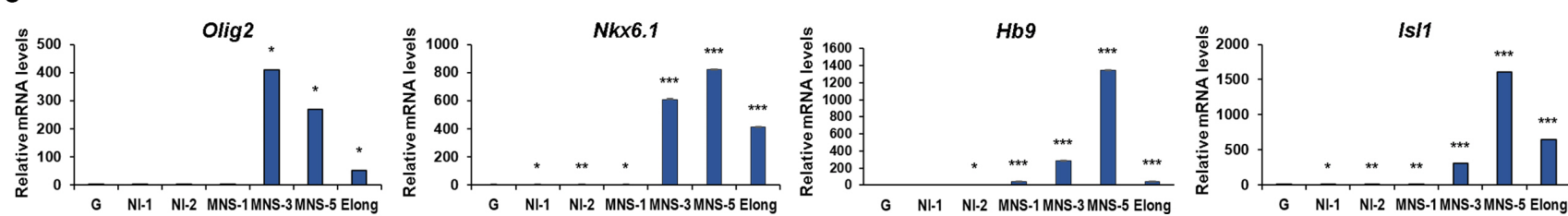

d
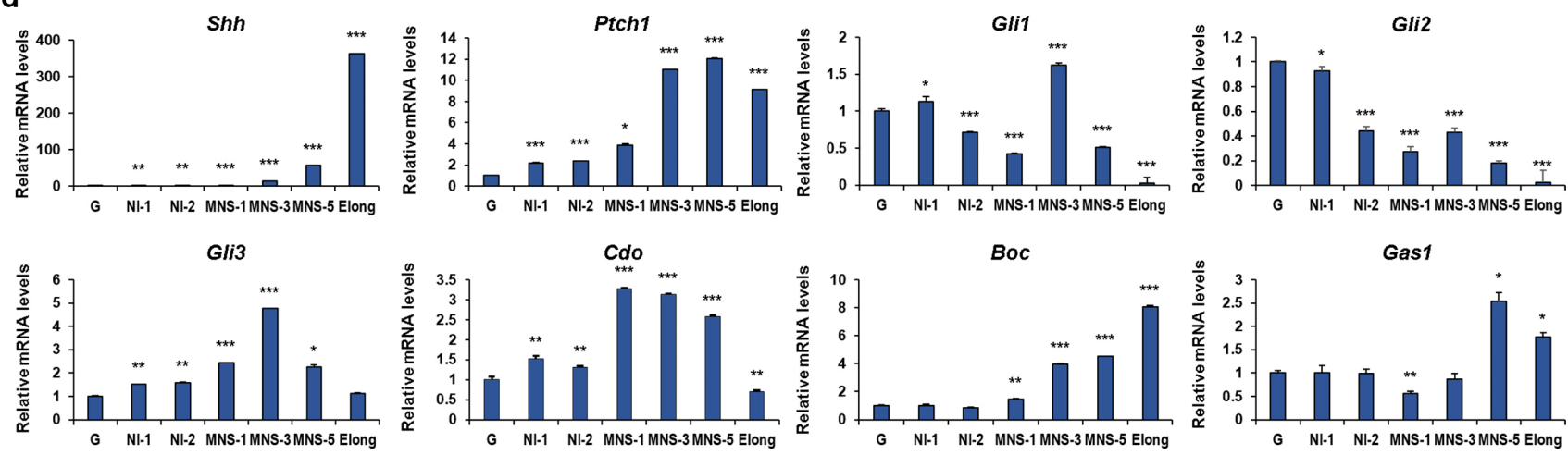

Fig. 1. The expression of genes implicated in specification and differentiation of ESCs into motor neurons. (a) The schematic representation of motor neuron differentiation used in this study. The detailed description of the procedure is presented in Materials and Methods. (b $\sim d)$ qRT-PCR analysis for the expression of stemness genes (Nanog and Oct4) (b), motor neuron differentiation markers (Olig2, Nkx6.1, Hb9 and Is/1) (c) and Shh signaling components (Shh, Ptch1, Gli1, Gli2, Gli3, Cdo, Boc and Gas1) (d) during specification and differentiation of mESCs into motor neuron. L32 was selected as a reference gene. Data represent means \pm SEM. ${ }^{*} \mathrm{p}<0.05,{ }^{* *} \mathrm{p}<0.01, * * * \mathrm{p}<0.001(\mathrm{n}=3$, each). 
creased until MNS-3 and decreased thereafter. Shh coreceptor genes, $C d o$ and $B o c$ were elevated at MNS-1 and stayed at a high level during MNS. Cdo expression was blunted at Elong, while Boc expression further increased at Elong. This increase of $B o c$ might be associated its role in axon guidance (27). Furthermore, the expression of $C d o$ during motor neuron differentiation was confirmed by immunoblot analysis showing a similar expression pattern as shown in qRT-PCR data (Supplementary Fig. S2). In contrast, the expression of another coreceptor, Gasl was greatly elevated at MNS-5. Among Shh coreceptors, Cdo appeared to be the earliest to be induced at MNS-1 prior to Shh signalling component genes, Shh and Ptchl. These data indicate that Cdo is the earliest acting Shh coreceptor that might correlate with motor neuron specification.

\section{Cdo deficiency altered gene expression in motor neuron specification of ES cells}

Before gaining insights into Cdo's functions in motor neuron specification, we decided to demonstrate clearly that among Shh coreceptors, Cdo is essentially required to motor neuron specification. For that we examined the levels of Boc and Gasl in Cdo-deficient cells at G stage by performing qRT-PCR (Supplementary Fig. S3). The result showed that the levels of $\mathrm{Boc}$ and $\mathrm{Gasl}$ in $\mathrm{Cdo}^{-/-}$cells were almost similar to those in $C d o^{+/+}$cells. Then, $C d o^{+/+}$ and $C d o^{-1-}$ cells at MNS-3 were harvested for gene expression profiling by RNA-sequencing analysis. The scatter plot images showed that 649 genes were up-regulated while 808 genes were down-regulated with 1.5-fold changes in $\mathrm{Cdo}^{-/-}$cells, relative to $\mathrm{Cdo}{ }^{+/+}$cells (Fig. 2a). The global gene expression was assessed by the reactome with Gene Set Enrichment Analysis (GSEA, http://software.broadinstitute.org) using MSigDB database v6.1 ( $\geq 1.5$ fold, $\mathrm{p}<0.05)$. The normalized enrichments score (NES) obtained from $\mathrm{Cdo} \mathrm{o}^{+/+}$and $\mathrm{Cdo} \mathrm{o}^{-/-}$cells revealed that the gene sets of the processes that contribute to neuronal development including proliferation, differentiation, synapse a

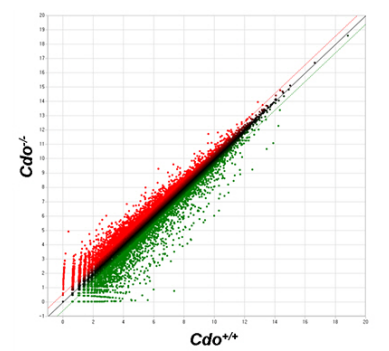

C

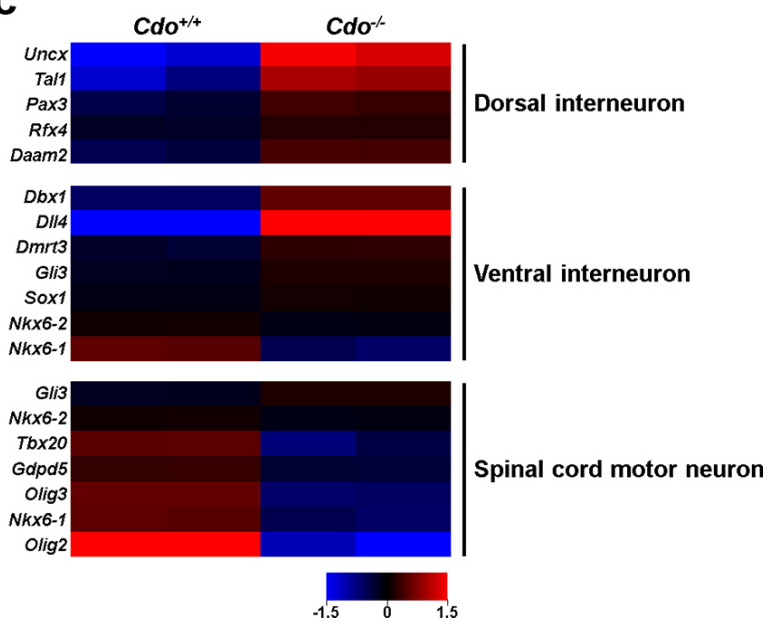

b

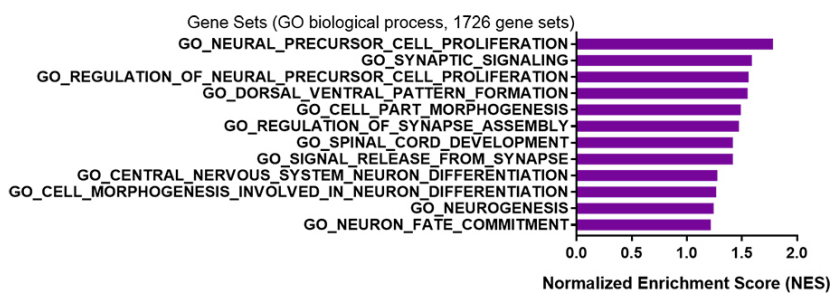

d

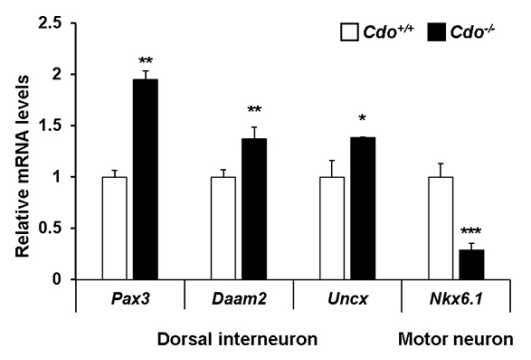

Fig. 2. Cdo deficiency altered gene expression in motor neuron specification of ES cells. (a) Scatter plot images of differentially expressed genes. Red and green colors indicate up- and down-regulated genes in $\mathrm{Cdo}^{-/-}$cells relative to $\mathrm{Cdo}^{+/+}$cells, respectively (1.5-fold change, $\mathrm{p}<0.05$ ). Black dots indicate genes with no significant change of RNA expression level (less than 1.5-fold change). (b) The bar charts indicate NES of the gene sets contributing to neuronal development in motor neuron specification-induced $\mathrm{Cdo}^{+/+}$and Cdo $^{-/-} \mathrm{cells}$. (c) Heat map for the relative levels of the gene sets related to dorsal-, ventral-interneuron and spinal cord motor neuron in Cdo ${ }^{-1-}$ cells compared to $\mathrm{Cdo}^{+/+}$cells at MNS-3. Red=Up-regulated genes, Blue=Down-regulated genes. (d) qRT-PCR analysis for dorsal interneuron regulators (Pax3, Daam2 and Uncx) and motor neuron specific gene (Nkx6.1) in $\mathrm{Cdo}^{+/+}$and $\mathrm{Cdo}^{-l-}$ cells at MNS-3. Each value was normalized to the level of $L-32$, an endogenous control. Data represent means \pm SEM. ${ }^{*} p<0.05,{ }^{*} \mathrm{p}<0.01,{ }^{* * *} \mathrm{p}<0.001$. 
formation and fate commitment were greatly enriched (Fig. 2b). The heat maps for genes related to dorsoventral patterning of the neural tubes showed that the expression of dorsal interneuron-related genes was higher in $\mathrm{Cdo}^{-/-}$ cells than in $C d o^{+/+}$cells, whereas the expression of the genes that are related to ventral interneuron and spinal cord moter neuron was reduced in $C d o^{-/-}$cells compared to that in $\mathrm{Cdo}{ }^{+/+}$cells (Fig. 2c). To confirm the RNA-sequencing data, motor neuron specification-induced $C d o^{+/+}$ and $C d o^{-1-}$ cells were subjected to qRT-PCR (Fig. 2d). The result revealed that the levels of dorsal interneuron regulators (Pax3, Daam2 and Uncx) were increased and the level of motor neuron specific gene $(N k x 6.1)$ was reduced in $\mathrm{Cdo}^{-/-}$cells compared to $\mathrm{Cdo}{ }^{+/+}$cells. Taken together, Cdo deficiency causes alteration in global gene expression related to motor neuron specfication, and dor- sal and ventral interneuron specfication.

\section{Cdo deficiency reduced the expression of ventral neuron markers with a concomitant increase in dorsal interneuron markers}

Based on the results of RNA-sequencing, we defined the effect of Cdo deficiency on motor neuron specification further. Total RNAs from $C d o^{+/+}$and $C d o^{-/-}$EBs at MNS-5 and Elong were subjected to qRT-PCR for the expression of genes implicated in ventral and motor neuron specification (Pax6, Olig2, Nkx6.1, Hb9, Isl1, Chx10) and dorsal interneuron specifiation (Brn3a, Pax2, Lbx1, Pax3). $C d o^{-1-}$ cells expressed significantly lower levels of Pax6, Olig2, Nkx6.1, Hb9, Isl1, and Chx10 at both time points, compared to $\mathrm{Cdo}^{+/+}$cells (Fig. 3a). Especially, the expression of Nkx6.1, Isll and Chx10 was greatly blunted in a

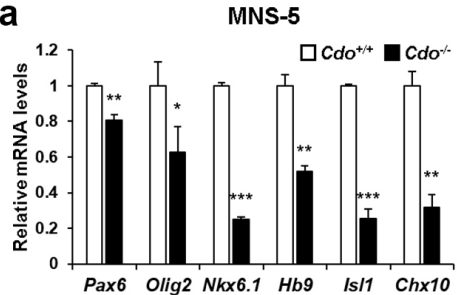

C

Olig2
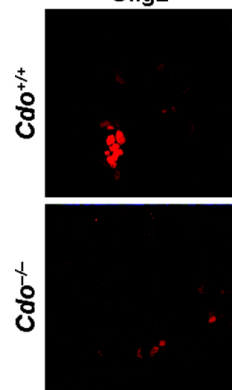

d

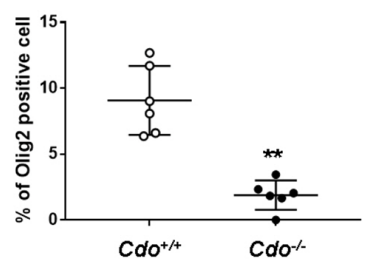

Nkx6.1
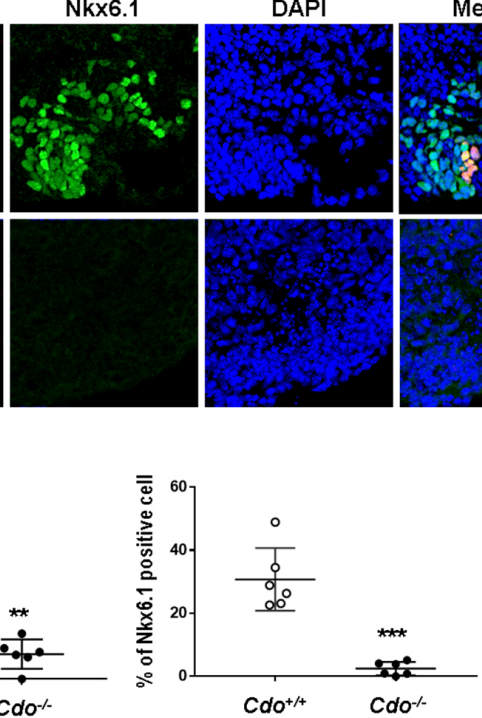

$\mathrm{Cdo}^{-1}$
Elong

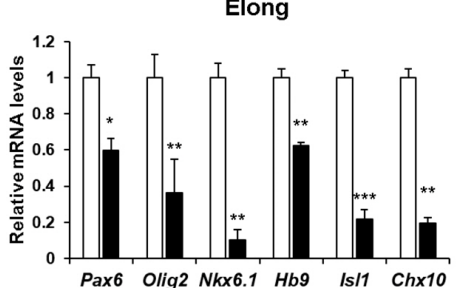

Merged
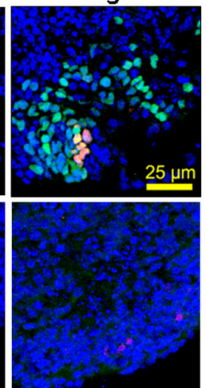
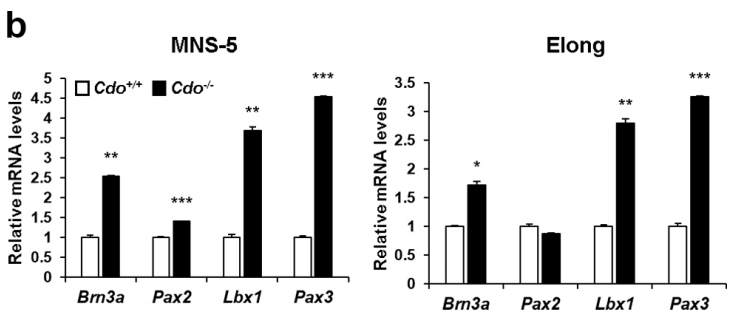

e

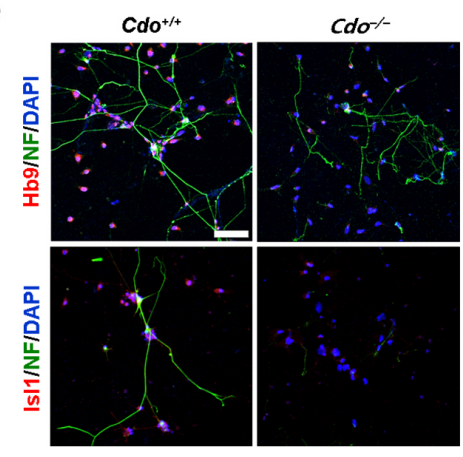

f

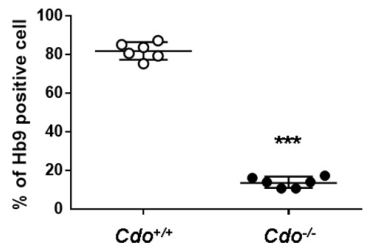

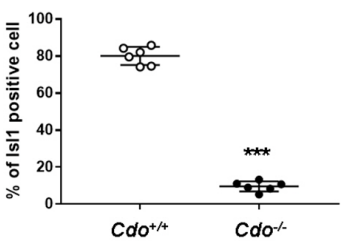

Fig. 3. $\mathrm{Cdo}^{-1-}$ ESCs displayed impaired motor neuronal specification. $(\mathrm{a}, \mathrm{b})$ qRT-PCR analysis for the levels of ventral and motor neuron specification markers (Pax6, Olig2, Nkx6.1, Hb9, Isl1 and Chx10) (a) and dorsal interneuron specification markers (Brn3a, Pax2, Lbx1 and Pax3) (b) in $\mathrm{Cdo}^{+/+}$and $\mathrm{Cdo}^{-/-} \mathrm{mESCs}$ at MNS-5 and Elong stages. L32 was selected as a reference gene. Data represent means \pm SEM. ${ }^{*} \mathrm{p}<0.05,{ }^{* *} \mathrm{p}<0.01, * * * \mathrm{p}<0.001$. ( $\mathrm{n}=3$, each) (c) Immunofluorescent staining for motor neuronal markers (Olig2 and Nkx6.1) in Cdo ${ }^{+/+}$ and $\mathrm{Cdo}^{-1-}$ EBs at MNS-5. Nuclei were visualized by DAPI. Size bar $=25 \mu \mathrm{m}$. (d) Quantification of Olig2- and Nkx6.1-positive cells shown in panel c. Data represent means \pm SD. ${ }^{* *} \mathrm{p}<0.01,{ }^{* * *} \mathrm{p}<0.001 .(\mathrm{n}=6)(\mathrm{e})$ Immunofluorescent staining for motor neuronal markers $(\mathrm{Hb9}$ and Isl1) in $\mathrm{Cdo}^{+/+}$and $\mathrm{Cdo}^{-1-}$ cells at Elong stage. NF was also immunostained as a neuronal differentiation marker. Nuclei were visualized by DAPI. Size bar $=10 \mu \mathrm{m}$. (f) Quantification of Hb9- and Isl1-positive cells shown in panel e. Data represent mean $\pm \mathrm{SD}$. ${ }^{* * *} \mathrm{p}<0.001$ $(n=6)$. 
$C d o^{-1-}$ cells. In contrast, the dorsal interneuron regulators, Brm 3a, $\mathrm{Lbxl}$ and Pax3 were greatly elevated in $\mathrm{Cdo}^{-/-}$cells at both MNS-5 and Elong, compared to those in $C d o^{+/+}$ cells, while the expression of Pax2 was only mildly increased at MNS-5 (Fig. 3b). These data suggest that Cdo is required for adequate specification of ventral neurons in response to Shh.

To further confirm the result, $\mathrm{Cdo}^{+/+}$and $C d o^{-/-} \mathrm{EBs}$ at MNS-5 were cryosectioned and immunofluorescent stained for Olig2 and Nkx6.1 (Fig. 3c and 3d). Similarly
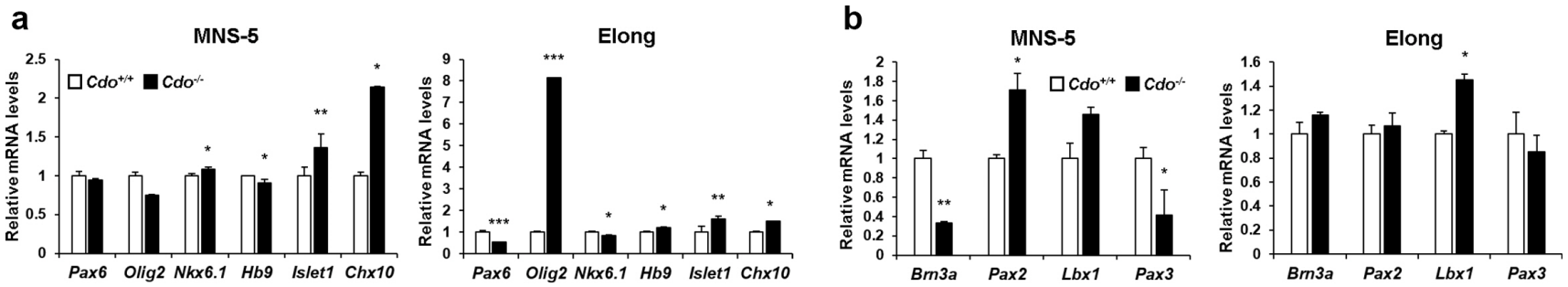

C

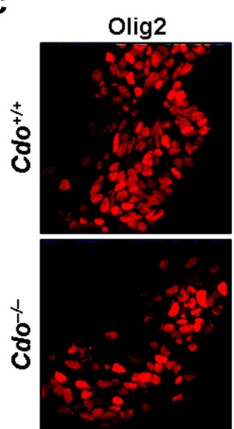

Nkx6.1
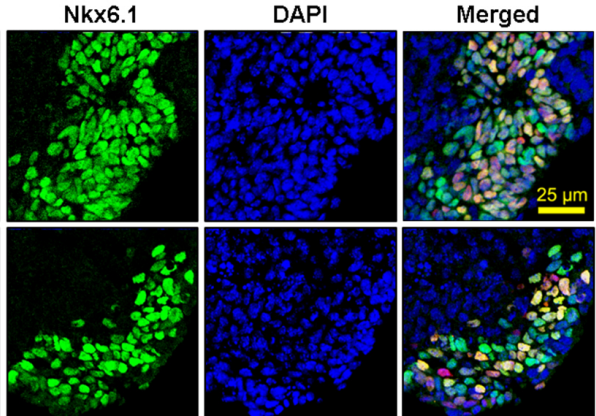

d
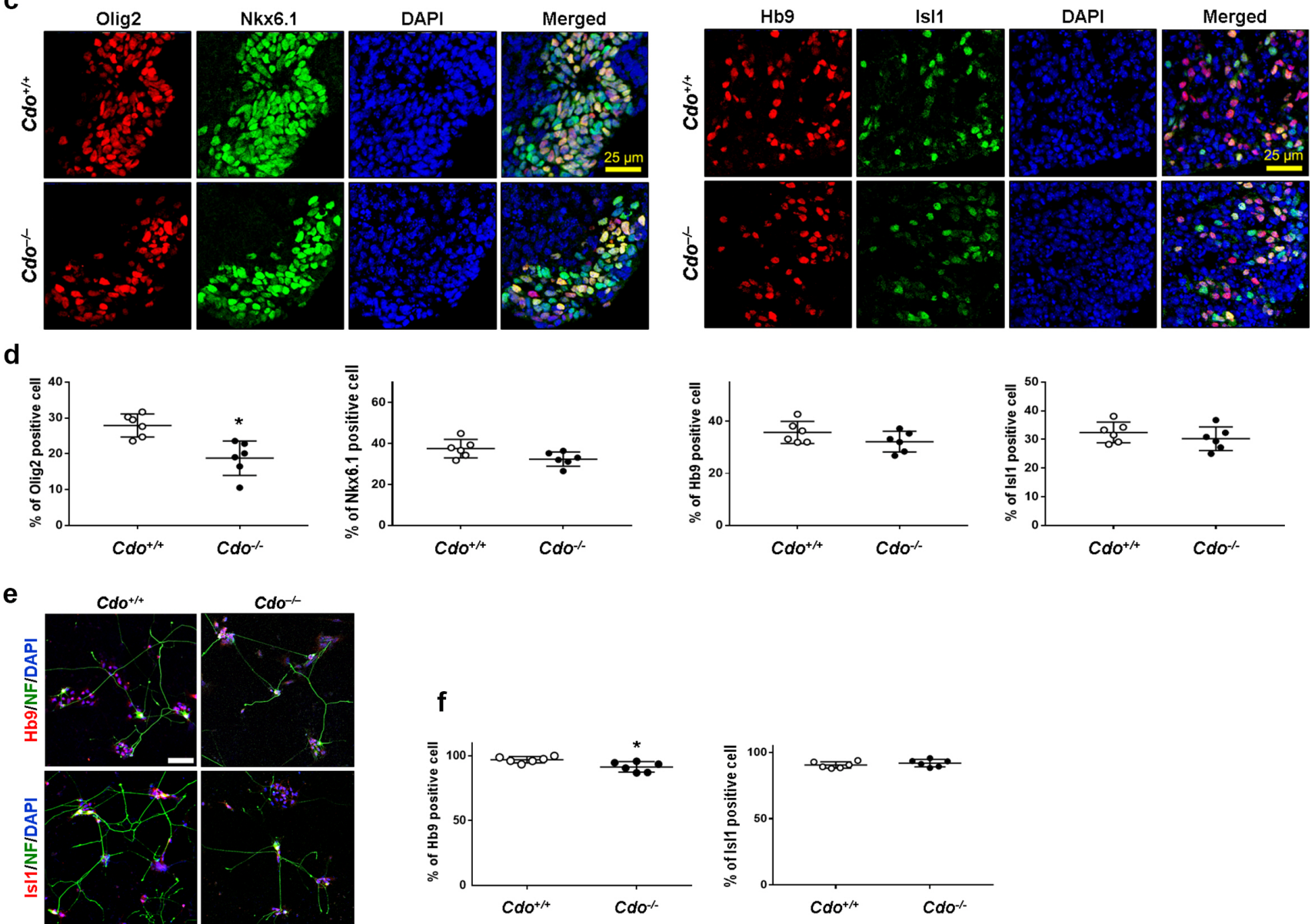

Fig. 4. Shh-independent activation by SAG restored motor neuron differentiation in Cdo-deficient ESCs. To activate Shh signaling pathway in Shh-independent way, $\mathrm{Cdo}^{+/+}$and $\mathrm{Cdo}^{-/-}$ESCs were treated with $1 \mu \mathrm{M} \mathrm{SAG}$ instead of Shh during MNS stage. (a, b) qRT-PCR analysis for genes related to ventral neural subtypes and motor neuron specification (Pax6, Olig2, Nkx6.1, Hb9, Isl1 and Chx10) (a) and dorsal interneuron specification (Brn3a, Pax2, Lbx1 and Pax3) (b) in $\mathrm{Cdo}^{+/+}$and $C d o^{-1-}$ ESCs at MNS-5 and Elong. L32 was selected as a reference gene. Data represent means \pm SEM. ${ }^{*} \mathrm{p}<0.05,{ }^{* *} \mathrm{p}<0.01,{ }^{* * *} \mathrm{p}<0.001$. ( $\mathrm{n}=3$, each) (c) Immunostaining for Olig2/Nkx6.1 or Hb9//sl1 in $\mathrm{Cdo}^{+/+}$and $\mathrm{Cdo}^{-/-}$EBs at MNS-5. DAPI was used to visualize nuclei. Size bar $=25 \mu \mathrm{m}$. (d) Quantification of Olig2-, Nkx6.1-, Hb9- and Isl1-positive cells shown in panel c. Data represent means \pm SD. ${ }^{*} \mathrm{p}<0.05$. ( $\mathrm{n}=6$, each) (e) Immunostaining for $\mathrm{Hb} 9$ or Isl1 in Cdo ${ }^{+/+}$ and $\mathrm{Cdo}^{-1-}$ cells at Elong. NF was immunostained indicating neuronal differentiation. Nuclei were visualized by DAPI. Size bar $=10 \mu \mathrm{m}$. (f) Quantification of Hb9- or Isl1-positive cells shown in panel e. Data represent means \pm SD. ${ }^{*} \mathrm{p}<0.05(\mathrm{n}=6)$. 
to the data obtained from qRT-PCR analysis, $C d o^{-/-}$EBs had greatly diminished numbers of Olig2- (4.8-fold reduction, $\mathrm{Cdo}^{+/+} ; 9.08 \%$ vs $\left.\mathrm{Cdo}^{-/-} ; 1.88 \%\right)$ or Nkx6.1-positive cells (12.4-fold reduction, $\mathrm{Cdo}^{+/+} ; 30.74 \%$ vs $\mathrm{Cdo}^{-/-}$; $2.47 \%$ ), compared to $\mathrm{Cdo}^{+/+}$EBs. Furthermore, $\mathrm{Cdo}{ }^{+/+}$ and $C d o^{-1-}$ cells at MNS-5 were dissociated and proceeded to elongation by culturing on the matrigel-coated coverslips for 3 days, followed by coimmunostaining for $\mathrm{Hb} 9$ or Isll together with Neurofilament $(\mathrm{NF})$ as a neuronal marker (Fig. 3e and 3f). Similarly to the marker analysis, significantly less Hb9- (5.9-fold reduction, $\mathrm{Cdo}^{+/+}$; 81.86\% vs $\left.C d o^{-1-} ; 13.8 \%\right)$ or Isll-positive cells (8.3-fold reduction, $\mathrm{Cdo}^{+/+} ; 80.1 \%$ vs $\left.\mathrm{Cdo}^{-/-} ; 9.66 \%\right)$ were found in the Cdo-deficient culture, compared to $C d o^{+/+}$culture. In addition, analysis of protein levels for $\mathrm{Hb} 9$ and Isll also revealed that each level of motor neuron markers was reduced in Cdo-deficient cells (Supplementary Fig. S4). Taken together, Cdo deficiency results in impaired motor neuron specification.

\section{The administration of a Shh agonist SAG restored motor neuron specification in Cdo-deficient ESCs}

In an effort to uncover the role of Cdo as a coreceptor in the regulation of Shh signalling pathway during motor neuron specification, we reactivated Shh signalling pathway in Cdo-deficient ESCs by adding $1 \mu \mathrm{M}$ SAG insted of Shh for the whole 5 days of MNS stage. SAG binds to Smo directly and leads to circumvent receptor-mediated activation. The reduced expression of Pax6, Nkx6.1 and $\mathrm{Hb} 9$ in $\mathrm{Cdo}^{-1-}$ cells (Fig. 3a) was nearly restored similarly to the level of $\mathrm{Cdo}^{+/+}$cells when SAG was treated (Fig. 4a). Additionally, the expression of $C h \times 10$ was even higher in $\mathrm{Cdo}^{-/-}$cells at MNS-5 and Olig2 was significantly elevated in $\mathrm{Cdo}^{-/-}$cells at Elong, compared to that of $\mathrm{Cdo}{ }^{+/+}$ cells. Even though the level of Pax2 and $L b x 1$ was still higher in $\mathrm{Cdo} \mathrm{o}^{-/-}$cells at MNS-5 compared to $\mathrm{Cdo}{ }^{+/+}$cells, the expression of Brn3a and Pax3 was significantly reduced in $C d o^{-1-}$ cells at MNS-5 (Fig. 4b). To gain insights further, SAG-treated $\mathrm{Cdo}^{+/+}$and $\mathrm{Cdo}{ }^{-/-}$EBs at MNS-5 were cryosectioned and immunostained for Olig2/Nkx6.1 or $\mathrm{Hb} 9 / \mathrm{Isll}$ (Fig. 4c and 4d). $\mathrm{Cdo}^{-/-}$EBs contained greatly elevated Olig2- and Nkx6.1-expressing cells, compared to the data shown in Fig. $3 c$ and $d$. In addition, the expression of $\mathrm{Hb} 9$ and Isll was also restored in $\mathrm{Cdo}^{-/-} \mathrm{EBs}$, relative to the $\mathrm{Cdo}{ }^{+/+}$EBs. Furthermore, cells at the Elong stage were immunofluorescent stained for Isll/NF

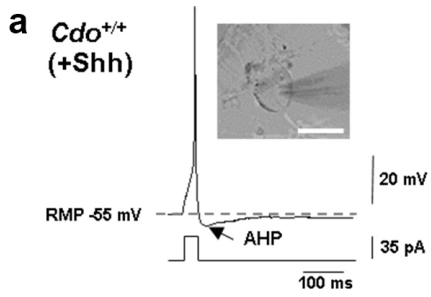

b $\mathrm{Cdo}^{\%}$

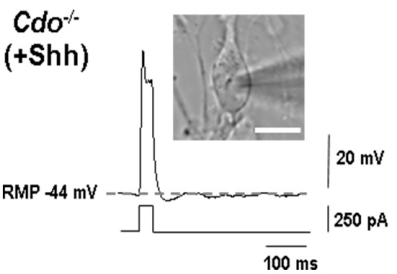

C

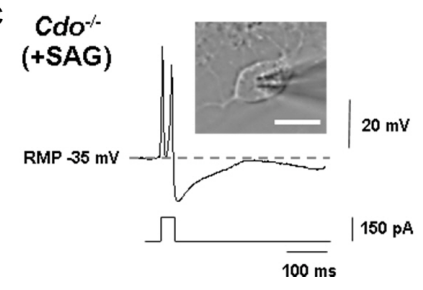

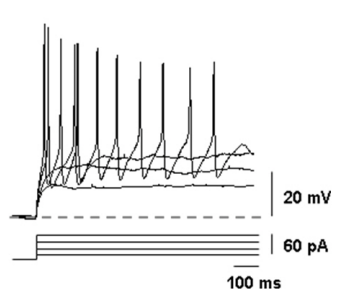
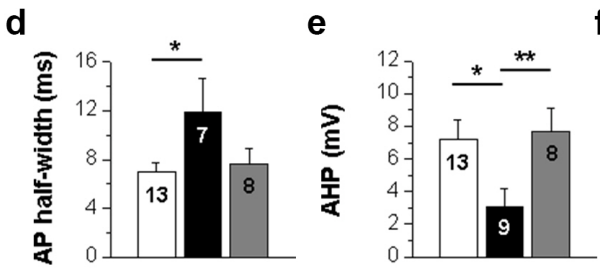

g
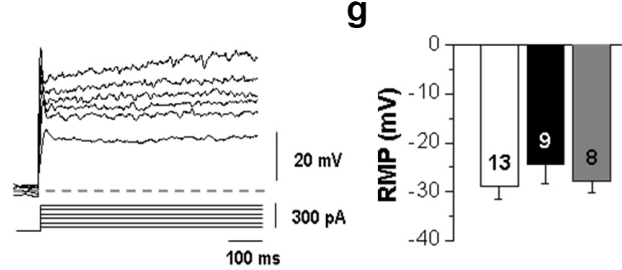

h

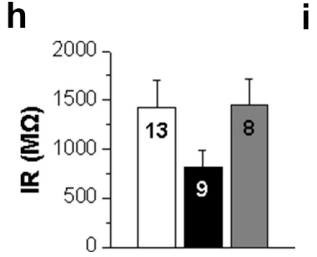

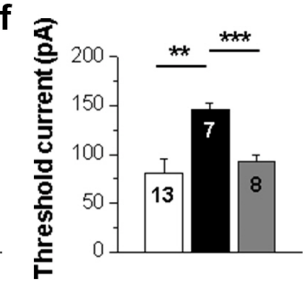

i

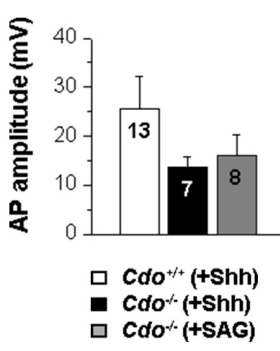

Fig. 5. SAG restored functional maturation of $\mathrm{Cdo}^{-1-}$ ESC-derived motor neurons. (a $\left.\sim \mathrm{c}\right)$ Differential interference contrast (DIC) images and representative trace of a whole-cell current clamp recording from $\mathrm{Cdo}^{+/+}$ESC-derived motor neurons, which were differentiatated with Shh (a) or $\mathrm{Cdo}^{-1-}$ ESC-derived motor neurons, which were exposed to Shh (b) or SAG (c) for differentiation. $\left(\mathrm{n}=13 \mathrm{for} \mathrm{Cdo}{ }^{+/+}(+\mathrm{Shh})\right.$, $\mathrm{n}=9$ for $\mathrm{Cdo}^{-1-}$ (+Shh), $\mathrm{n}=8$ for $\mathrm{Cdo}^{-1-}$ (+SAG)) Scale bars=10 $\mu \mathrm{m}$. (d $\left.\sim \mathrm{i}\right)$ Evoked action potentials generated in response to a depolarizing current injection. Graphs comparing the passive membrane properties. The sample size (n-number) is indicated in each graph. Values are means \pm SEM. ${ }^{*} \mathrm{p}<0.05,{ }^{* *} \mathrm{p}<0.01,{ }^{* * *} \mathrm{p}<0.001$. 
or $\mathrm{Hb} 9 / \mathrm{NF}$ (Fig. 4e and 4f). SAG treatment restored the motor neuron specification in Cdo-deficient cells to the similar level of $\mathrm{Cdo}^{+/+}$cells. However, the numbers of $\mathrm{NF}$-immunostained cells were still fewer in $C d o^{-/-}$cells compared to $C d o^{+/+}$cells, indicating that Cdo-mediated Shh signalling activation seems to regulate neuronal differentiation in a different way from SAG-induced activation of Shh signalling pathway. Taken together, these data suggest that Cdo as a Shh coreceptor contributes to ventral neuron specification via Shh signalling activation.

\section{SAG treatment restored functional maturation of $\mathrm{Cdo}^{-1-}$ ESCs-derived neurons}

To examine the electrophysiological properties of neurons derived from $\mathrm{Cdo}^{+/+}$and $\mathrm{Cdo}^{-/-}$ESCs, we carried out whole-cell patch-clamp recordings. We found that action potential firing patterns of $\mathrm{Cdo}^{-/-}$ESCs-derived neurons were quite immature, judged by inability to fire repetitively upon depolarizing current injection (Fig. 5a and $5 b$ ), the broad AP, small AHP, and increased threshold current (Fig. 5d f). All of $\mathrm{Cdo}^{+/+}$ESCs-derived neurons fired APs in response to a prolonged ( $1 \mathrm{sec}$ ) depolarizing current injection in current-clamp recordings while none of $\mathrm{Cdo}^{-1-}$ ESCs-derived neurons fired more than a single AP. SAG treatment restored an ability to fire repetitive $\mathrm{APs}$ in respone to depolarizing current injecion in $\mathrm{Cdo}^{-/-}$ ESCs-derived neurons (Fig. 5c) with a concomitant rescue of AP half width, AHP, and threshold current (Fig. $5 \mathrm{~d} \sim \mathrm{f}$ ). RMP, IR and AP amplitudes were not affected by Cdo deficiency (Fig. $5 \mathrm{~g} \sim \mathrm{i}$ ). Taken together, these data suggest that Cdo is required for the functional maturation of ESCs-derived neurons as a Shh coreceptor.

\section{Discussion}

The requirement of Shh signalling activity for the efficient generation of ventral neurons has been demonstrated by several previous studies $(10,28,29)$. In this study, we attempted to address the defined function of Cdo as a Shh coreceptor in motor neuron generation. Multiple studies have underlined the importance of Cdo in Shh signalling pathwary and neural tube patterning $(13,17,30)$. In spite of distinct requirements of three coreceptors, Cdo, Boc, and Gas1 for Shh signalling pathway in a developmental process, the defined function of each coreceptor is still imcompletely understood. Cdo single and Cdo/Boc double mutant mice exhibit defects in neural tube patterning related to impaired Shh signalling pathway $(13,14)$. However, these coreceptors are not required for other Shh signalling-controlled developmental processes (14). Cdo/Boc/Gas1 triple knockout mice exhibit almost equivalent phenotype of mice lacking Shh, suggesting that these coreceptors are essential for Shh signal transduction. The expression of all three coreceptors in motor neuron generation of ESCs is consistent with their expression pattern in the neural tube development $(31,32)$. Our data suggest that there is a temporal difference of gene induction which might reflect their action in the multiple stages of motor neuron generation. Cdo expression was induced and stayed high during mortor neuron specification, while Boc expression was progressively increased in motor neuron generation. Gasl was induced later than Cdo and Boc in this process. Thus, it is likely that Cdo might be the earliest acting Shh coreceptor that might be critical for motor neuron specification.

Shh signalling pathway has been proposed to play a stage-specific function in the specification of ventral neuronal subtypes $(5,12,31,33)$. In the early stage, Shh signalling pathway is critical for the specification of the most ventral cell type Nkx2.2-positive V3 interneuron and later, it is required for the maintenance of Olig2-positive motor neuron progenitors (34). This is consistent with the current data showing that Olig2 levels were mildly decreased in Cdo-deficient cells at MNS-5 while subsequently at Elong stage, the levels were significantly affected. Unlike Olig2, the expression of Nkx6.1 together with Isl1 and Chx10 was greatly reduced in Cdo-deficient cells at MNS-5. Our data is consistent with the reported role of $\mathrm{Nkx6.1}$ in motor neuron specification. Nkx6.1 is expressed in motor neuron, V2 and V3 interneuron progenitors. Also, mice lacking Nkx6.1 display an impairment in motor neuron and V2 interneuron specification with diminished expression of $\mathrm{Hb} 9$ and Isll (35). Previous studies have reported that weakened Shh signalling activity causes a shift of ventral to dorsal neuronal patterning (8, 31, 32). Consistently, Cdo-deficient cells express significantly elevated dorsal interneuron markers, such as Brn3a, Pax2, Lbxl and Pax3 in response to Shh addition. The ventral to doral shift in Cdo-deficient cells was alleviated by the reactivation of Shh signalling pathway by SAG treatment. Among ventral markers, Olig2, Isl1 and Chx10 were expressed higher in Cdo-deficient cells in response to SAG, relative to the wildtype cells. Especially the level of Olig2 was still slightly reduced in Cdo-deficient cells at MNS-5 which was greatly elevated at the late stage of differentiation, likely reflecting a delayed motor neuron specfication. In addition, the dorsal neuron marker, Brn3a expression was greatly decreased while the level of Pax2 and Lbx1 was not fully suppressed in Cdo-deficient cells at MNS-5 in response to SAG treatment. These data suggest that 
Cdo might regulate a Shh-independent mechanism to suppress dorsal cell fate. RA and Shh signallings are essential for motor neuron specification $(28,36)$ and the inhibition of Notch signalling has been shown to provide a permissive signal for the motor neuron specification. Especially the forced expression of a Notch effector, Hes 5 inhibits motor neuron differentiation (37). The residual ventral to dorsal shift observed in Cdo-deficient cells likely reflects deregulated Notch signalling pathway. Consistently, the close examination of RNA sequencing result reveals that the level of Hes5 was elevated in Cdo-deficient cells relative to the wildtype cells (date not shown). Currently it is unkown whether Cdo regulates Notch signalling pathway. Other possibility is that Cdo might suppress Wnt signalling pathway critical for dorsal cell fate specification (4, 38). We have previously shown that Cdo inhibits Wnt signalling pathwat by interaction with a Wnt signal coreceptor, Lrp6 in the control of forebrain development (39). Cdo-deficiency causes hyperactive Wnt signalling resulting in expansion of dorsal cell fate. Considering the graded activity of Wnt signalling pathway is critical for dorsal ventral patterning, Cdo deficiency causes dysregulation of Wnt signalling contributing to ventral to dorsal shift. Our data further refine the function of Cdo in motor neuron specification, providing the mechanisms regulating differentiation of pluripotent stem cells into motor neurons. Discoveries along these lines would facilitate pluripotent stem cell-based regenerative medicine applications.

\section{Acknowledgments}

This research was supported by the National Research Foundation of Korea Grant funded by the Korean Government (MSIP) (NRF-2019R1A2C2006233, NRF-2017M3A9 D8048710 and NRF-2016R1A5A2945889 to JSK, NRF-201 6H1A2A1908679 to HK, and NRF-2018R1D1A1B0704166 1 to $\mathrm{YEL})$.

\section{Potential Conflict of Interest}

The authors have no conflicting financial interest.

\section{Supplementary Materials}

Supplementary data including one table and four figures can be found with this article online at http://pdf. medrang.co.kr/paper/pdf/IJSC/IJSC-13-s20037.pdf.

\section{References}

1. Jessell TM. Neuronal specification in the spinal cord: in- ductive signals and transcriptional codes. Nat Rev Genet 2000;1:20-29

2. Briscoe J, Ericson J. Specification of neuronal fates in the ventral neural tube. Curr Opin Neurobiol 2001;11:43-49

3. Briscoe J, Pierani A, Jessell TM, Ericson J. A homeodomain protein code specifies progenitor cell identity and neuronal fate in the ventral neural tube. Cell 2000;101:435-445

4. Helms AW, Johnson JE. Specification of dorsal spinal cord interneurons. Curr Opin Neurobiol 2003;13:42-49

5. Ericson J, Briscoe J, Rashbass P, van Heyningen V, Jessell TM. Graded sonic hedgehog signaling and the specification of cell fate in the ventral neural tube. Cold Spring Harb Symp Quant Biol 1997;62:451-466

6. Briscoe J, Chen Y, Jessell TM, Struhl G. A hedgehog-insensitive form of patched provides evidence for direct long-range morphogen activity of sonic hedgehog in the neural tube. Mol Cell 2001;7:1279-1291

7. Roelink H, Porter JA, Chiang C, Tanabe Y, Chang DT, Beachy PA, Jessell TM. Floor plate and motor neuron induction by different concentrations of the amino-terminal cleavage product of sonic hedgehog autoproteolysis. Cell 1995;81:445-455

8. Chiang C, Litingtung Y, Lee E, Young KE, Corden JL, Westphal H, Beachy PA. Cyclopia and defective axial patterning in mice lacking Sonic hedgehog gene function. Nature 1996;383:407-413

9. Bai CB, Auerbach W, Lee JS, Stephen D, Joyner AL. Gli2, but not Glil, is required for initial Shh signaling and ectopic activation of the Shh pathway. Development 2002;129: 4753-4761

10. Ericson J, Rashbass P, Schedl A, Brenner-Morton S, Kawakami A, van Heyningen V, Jessell TM, Briscoe J. Pax6 controls progenitor cell identity and neuronal fate in response to graded Shh signaling. Cell 1997;90:169-180

11. Dessaud E, Ribes V, Balaskas N, Yang LL, Pierani A, Kicheva A, Novitch BG, Briscoe J, Sasai N. Dynamic assignment and maintenance of positional identity in the ventral neural tube by the morphogen sonic hedgehog. PLoS Biol 2010;8:e1000382

12. Ericson J, Morton S, Kawakami A, Roelink H, Jessell TM. Two critical periods of Sonic Hedgehog signaling required for the specification of motor neuron identity. Cell 1996;87: 661-673

13. Allen BL, Tenzen T, McMahon AP. The Hedgehog-binding proteins Gasl and Cdo cooperate to positively regulate Shh signaling during mouse development. Genes Dev 2007;21: 1244-1257

14. Allen BL, Song JY, Izzi L, Althaus IW, Kang JS, Charron F, Krauss RS, McMahon AP. Overlapping roles and collective requirement for the coreceptors GAS1, CDO, and BOC in SHH pathway function. Dev Cell 2011;20:775-787

15. Zhang W, Yi MJ, Chen X, Cole F, Krauss RS, Kang JS. Cortical thinning and hydrocephalus in mice lacking the immunoglobulin superfamily member CDO. Mol Cell Biol 2006;26:3764-3772

16. Izzi L, Lévesque M, Morin S, Laniel D, Wilkes BC, Mille 
F, Krauss RS, McMahon AP, Allen BL, Charron F. Boc and Gasl each form distinct Shh receptor complexes with Ptch1 and are required for Shh-mediated cell proliferation. Dev Cell 2011;20:788-801

17. Tenzen T, Allen BL, Cole F, Kang JS, Krauss RS, McMahon AP. The cell surface membrane proteins Cdo and Boc are components and targets of the Hedgehog signaling pathway and feedback network in mice. Dev Cell 2006; 10:647-656

18. Kwon YR, Jeong MH, Leem YE, Lee SJ, Kim HJ, Bae GU, Kang JS. The Shh coreceptor Cdo is required for differentiation of midbrain dopaminergic neurons. Stem Cell Res 2014;13:262-274

19. Zhang W, Kang JS, Cole F, Yi MJ, Krauss RS. Cdo functions at multiple points in the Sonic Hedgehog pathway, and Cdo-deficient mice accurately model human holoprosencephaly. Dev Cell 2006;10:657-665

20. Zhang W, Hong M, Bae GU, Kang JS, Krauss RS. Boc modifies the holoprosencephaly spectrum of Cdo mutant mice. Dis Model Mech 2011;4:368-380

21. Bae GU, Domené S, Roessler E, Schachter K, Kang JS, Muenke M, Krauss RS. Mutations in CDON, encoding a hedgehog receptor, result in holoprosencephaly and defective interactions with other hedgehog receptors. Am J Hum Genet 2011;89:231-240

22. Jeong MH, Leem YE, Kim HJ, Kang K, Cho H, Kang JS. A Shh coreceptor Cdo is required for efficient cardiomyogenesis of pluripotent stem cells. J Mol Cell Cardiol 2016;93: 57-66

23. Jeong HJ, Lee HJ, Vuong TA, Choi KS, Choi D, Koo SH, Cho SC, Cho H, Kang JS. Prmt7 deficiency causes reduced skeletal muscle oxidative metabolism and age-related obesity. Diabetes 2016;65:1868-1882

24. Langmead B, Salzberg SL. Fast gapped-read alignment with Bowtie 2. Nat Methods 2012;9:357-359

25. Quinlan AR, Hall IM. BEDTools: a flexible suite of utilities for comparing genomic features. Bioinformatics 2010;26: 841-842

26. Gentleman RC, Carey VJ, Bates DM, Bolstad B, Dettling M, Dudoit S, Ellis B, Gautier L, Ge Y, Gentry J, Hornik $\mathrm{K}$, Hothorn T, Huber W, Iacus S, Irizarry R, Leisch F, Li C, Maechler M, Rossini AJ, Sawitzki G, Smith C, Smyth G, Tierney L, Yang JY, Zhang J. Bioconductor: open software development for computational biology and bioinformatics. Genome Biol 2004;5:R80

27. Okada A, Charron F, Morin S, Shin DS, Wong K, Fabre PJ, Tessier-Lavigne M, McConnell SK. Boc is a receptor for sonic hedgehog in the guidance of commissural axons. Nature 2006;444:369-373

28. Wichterle H, Lieberam I, Porter JA, Jessell TM. Directed differentiation of embryonic stem cells into motor neurons. Cell 2002;110:385-397

29. Pierani A, Brenner-Morton S, Chiang C, Jessell TM. A sonic hedgehog-independent, retinoid-activated pathway of neurogenesis in the ventral spinal cord. Cell 1999;97:903915

30. Ribes V, Briscoe J. Establishing and interpreting graded Sonic Hedgehog signaling during vertebrate neural tube patterning: the role of negative feedback. Cold Spring Harb Perspect Biol 2009;1:a002014

31. Lee J, Platt KA, Censullo P, Ruiz i Altaba A. Glil is a target of Sonic hedgehog that induces ventral neural tube development. Development 1997;124:2537-2552

32. Litingtung Y, Chiang C. Specification of ventral neuron types is mediated by an antagonistic interaction between Shh and Gli3. Nat Neurosci 2000;3:979-985

33. Ericson J, Muhr J, Placzek M, Lints T, Jessell TM, Edlund T. Sonic hedgehog induces the differentiation of ventral forebrain neurons: a common signal for ventral patterning within the neural tube. Cell 1995;81:747-756

34. Takebayashi H, Nabeshima Y, Yoshida S, Chisaka O, Ikenaka K, Nabeshima Y. The basic helix-loop-helix factor olig2 is essential for the development of motoneuron and oligodendrocyte lineages. Curr Biol 2002;12:1157-1163

35. Sander M, Paydar S, Ericson J, Briscoe J, Berber E, German M, Jessell TM, Rubenstein JL. Ventral neural patterning by Nkx homeobox genes: Nkx6.1 controls somatic motor neuron and ventral interneuron fates. Genes Dev 2000; 14:2134-2139

36. Novitch BG, Wichterle H, Jessell TM, Sockanathan S. A requirement for retinoic acid-mediated transcriptional activation in ventral neural patterning and motor neuron specification. Neuron 2003;40:81-95

37. Yang X, Tomita T, Wines-Samuelson M, Beglopoulos V, Tansey MG, Kopan R, Shen J. Notchl signaling influences v2 interneuron and motor neuron development in the spinal cord. Dev Neurosci 2006;28:102-117

38. Ciani L, Salinas PC. WNTs in the vertebrate nervous system: from patterning to neuronal connectivity. Nat Rev Neurosci 2005;6:351-362

39. Jeong MH, Ho SM, Vuong TA, Jo SB, Liu G, Aaronson SA, Leem YE, Kang JS. Cdo suppresses canonical Wnt signalling via interaction with Lrp6 thereby promoting neuronal differentiation. Nat Commun 2014;5:5455 